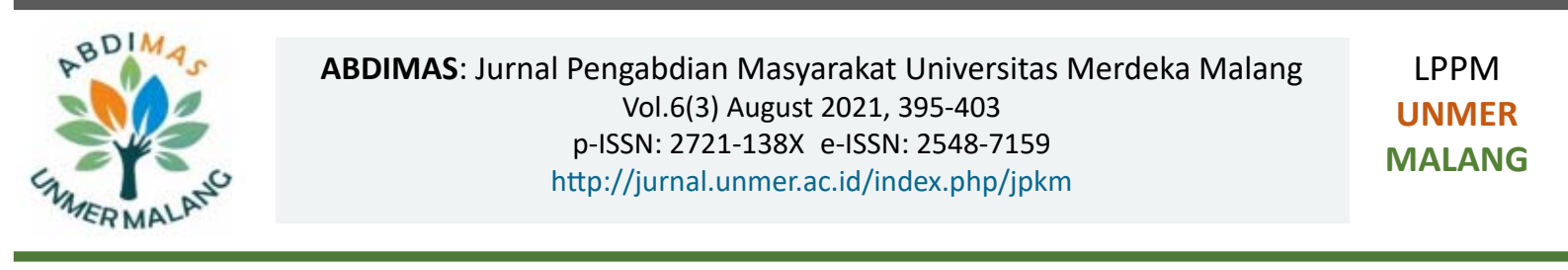

\title{
Pelatihan Penelusuran E-Resources untuk Penyusunan Artikel Ilmiah bagi Guru-Guru di Kabupaten Tuban
}

\author{
Imas Cintamulya', Mu'jizatin Fadiana² \\ 'Departemen Pendidikan Biologi, Fakultas Keguruan dan Ilmu Pendidikan, ²Departemen Pendidikan Matematika, \\ Fakultas Keguruan dan Ilmu Pendidikan Universitas PGRI Ronggolawe \\ Jl. Manunggal No.61, Tuban, 62381, Indonesia
}

\begin{abstract}
ARTICLE INFO
\section{ABSTRACT}

Received: 2021-01-13 Revised: 2021-02-03

Accepted: 2021-03-23

Training in researching e-resources for the preparation of scientific articles for teachers in the Tuban district has been carried out. Teachers in the Tuban district have received training in researching e-resources for the preparation of scientific articles. This activity is carried out as an effort to improve teacher professionalism in writing scientific articles. This training aims to provide understanding and skills in researching e-resources for the preparation of scientific articles for teachers in Tuban Regency. This training participant is limited to 15 people, considering that they are still in a COVID-19 condition.

Keywords: The method used is a lecture combined with a discussion during the socialization. The demonstration method is carried out during the e-resources research activities. Meanwhile, to record the activities

E-resources, Scientific article, Teacher profession, The teachers, Training of training participants through documentation. Based on the assignment to search for articles from Science Direct, Google Advance, Garuda, Library Genesis, Sinta, DOAJ, and Scopus, the results showed that all participants scored above 90 on average. resources for finding scientific articles of research results are very good.
\end{abstract}

(C)2021 Published by University of Merdeka Malang. This is an open access article distributed under the CC BY-SA 4.0 license (https://creativecommons.org/licenses/by-sa/4.0/)

How to cite: Cintamulya, I., \& Fadiana, M. (2021). Pelatihan Penelusuran E-Resources untuk Penyusunan Artikel IImiah bagi GuruGuru di Kabupaten Tuban. Abdimas: Jurnal Pengabdian Masyarakat Universitas Merdeka Malang, 6(3), 395-403. https://doi.org/10.26905/abdimas.v6i3.5318

\section{PENDAHULUAN}

Dalam dekade terakhir pengembangan profesional guru telah menjadi pusat perhatian tidak hanya di Indonesia tapi juga di negara-negara lain (Moutafidou et al., 2012). Menjadikan guru lebih berkualitas dan profesional yang tinggi, merupakan hal yang perlu dilakukan, supaya guru bisa mengembangkan peran sentralnya untuk siap mengidentifikasi dan menghadapi kondisi sosial, politik, dan budaya. Di sisi lain, pesatnya perkembangan ilmu pengetahuan dan teknologi pada abad 21 menuntut semua individu tak terkecuali guru untuk paham tentang budaya digitalisasi dan komputerisasi. Hal ini berdampak juga terhadap tuntutan pemerintah dan masyarakat terhadap profesionalitas guru semakin meningkat. 
ABDIMAS: Jurnal Pengabdian Masyarakat Universitas Merdeka Malang Volume 6, No. 3, August 2021: 395-403

Oleh karena itu, budaya digital dan komputerisasi dapat menjadi sarana dalam mendukung peningkatan profesionalismeguru. Banyak carayang bisa dilakukan seorang pendidik dalam meningkatkan profesionalisme dan membangun keterampilan literasi informasi, diantaranya, pembelajaran seumur hidup, penelitian, dan menulis artikel ilmiah berbasis penelitian (Moutafidou et al., 2012; McMillen et al., 2010). Kewajiban guru di Indonesia untuk menulis artikel ilmiah tertuang dalam Peraturan Menteri Pendayagunaan Aparatur Negara dan Reformasi Birokrasi (PerMenPAN-RB) No. 16/2009 tentang Jabatan Fungsional Guru dan Angka Kreditnya. Guru diharapkan melakukan pengembangan profesi berkelanjutan melalui pembuatan karya tulis ilmiah di bidang pendidikan formal dan pembelajaran pada satuan pendidikannya. Maka menulis karya ilmiah merupakan syarat mutlak bagi guru dalam rangka untuk pengembangan karir atau jabatan fungsional, yang merupakan keharusan (Depdiknas Dirjen Dikdasmen Direktorat Tenaga Kependidikan, 2001).

Mengapa menulis ilmiah penting dalam pengembangan profesionalisme guru. Merujuk pada pendapat McMillen et al. (2010) bahwa menulis merupakan suatu komunikasi yang penting serta proses kunci untuk mendorong pemikirian kritis. Melalui penulisan artikel berbasis penelitian, guru dituntut menjadi praktisi yang reflektif dalam memahami dan mengevaluasi situasi praktis melalui penelitian, mendefinisikan kembali semua asumsi yang diberikan, selanjutnya guru akan diberdayakan dalam hal keterampilan untuk mengangkat suatu permasalahan berdasarkan peninjauan, mencari bukti, dan mengevaluasi data secara kritis (Moutafidou et al., 2012). Selanjutnya Smiles \& Short (2006) mengemukakan tentang manfaat yang bisa diperoleh dari menulis artikel ilmiah bagi pendidik adalah: (1) Memperdalam dan memperluas pemahaman menulis; (2) Memberikan kepuasan profesional dan rasa pencapaian; (3) Meningkatkan kepercayaan diri dan rasa diri sebagai seorang profesional; (4) Memberdayakan pendidik untuk mendorong perubahan; (5) Mendorong sikap yang lebih aktif dalam percakapan tentang praktik dan kebijakan pendidikan, di semua tingkatan; (6) Memperluas audiens profesional guru; dan (7) Mengurangi isolasi dan menghubungkan guru dengan rekan kerja dan komunitas.

Namun antara tuntutan kewajiban guru untuk menulis karya ilmiah dengan kenyataan di lapangan masih belum sejalan dengan yang diharapkan. Guru-guru masih banyak yang mengalami kendala dalam penulisan karya ilmiah khususnya penulisan artikel untuk diterbitkan di jurnal nasional. Kendala yang dihadapi guru dalam penulisan artikel terutama dalam hal: (1) Tidak menggunakan sumber primer (Jurnal/Conference); (2) Pustaka yang digunakan tidak mutakhir/tahun lama; (3) Penulisan kutipan yang salah, tidak konsisten mengikuti salah satu gaya; dan (4) Penulisan daftar pustaka yang salah, tidak konsisten mengikuti salah satu gaya. Untuk mendapatkan sumber primer dan pustaka mutakhir pada saat ini sebenarnya bukan merupakan hal yang sulit. Melalui penggunaan teknologi informasi kedua masalah tersebut dapat terselesaikan.

E-resources menjadi sangat berguna dan banyak digunakan dalam menyelesaikan permasalahan penulisan artikel (Siwach \& Malik, 2018). Seperti yang ditulis pada banyak literatur, beberapa tahun terakhir ini e-resources paling banyak digunakan dalam hal pengumpulan informasi. E-resources meliputi pengambilan database, full-text secara online; sumber e-reference, sumber internet, e-journal, dan e-book (Mondal \& Maity, 2016; Elavazhagan \& Udayakumar, 2013). Hasil studi Adegbore (2011) mengungkapkan bahwa para akademisi telah menunjukkan kepuasan dengan penggunaan e-resources 


\section{Pelatihan Penelusuran E-Resources untuk Penyusunan Artikel Ilmiah bagi Guru-Guru di Kabupaten Tuban}

Imas Cintamulya, Mu'jizatin Fadiana

karena penggunaannya mengarah pada peningkatan penelitian dan komunikasi ilmiah yang lebih baik. Khususnya database online seperti Emerald, EBSCO, dan Proquest (Uplaonkar \& Keshava, 2013). Melalui tersedianya database online seperti sekarang ini dapat kita manfaatkan dalam penulusuran artikel-artikel yang relevan untuk mendukung penyusunan artikel yang dibuat. Informasi hasil penelitian di era digital ini begitu melimpah, hanya saja para penulis tak terkecuali guru masih belum familiar mencari infomasi tersebut melalui pemanfaatan database seperti EBSCO, ProQuest, Garuda, Sinta, Science Direct, Google Advance, dan Library genesis. Salah satu keuntungan dengan memanfaatkan database, artikel-artikel yang tersedia di database dapat diakses secara full-text (Maryatun \& Irianti, 2016).

Merujuk pada kewajiban guru untuk memiliki kompetensi dan keterampilan dalam menulis artikel ilmiah dan menyelaraskan dengan budaya digitalisasi dan komputerisasi di abad 21 ini, serta dalam rangka penyelenggaraan Tri Dharma Perguruan Tinggi bagi dosen, maka perlu dilakukan kegiatan pengabdian pada masyarakat. Untuk itu penulis dengan Tim pengabdian pada masyarakat Program Studi Magister Pendidikan Biologi Universitas PGRI Ronggolawe melakukan kegiatan "Pelatihan Penulusuran E-resources untuk Penyusunan Artikel Ilmiah bagi Guru-Guru di Kabupaten Tuban". Adapun tujuan dari kegiatan pengadian pada masyarakat ini adalah untuk memberikan pemahaman dan keterampilan dalam hal penulusuran e-resources untuk penyusunan artikel ilmiah bagi guru-guru di Kabupaten Tuban.

\section{METODE}

\section{Rancangan kegiatan}

Rancangan kegiatan yang dilakukan dalam pengabdian masyarakat melalui pelatihan penulusuran e-resources untuk penyusunan artikel ilmiah bagi guru-guru di Kabupaten Tuban meliputi 3 tahap, yaitu tahap persiapan, tahap pelaksanaan dan tahap evaluasi. Adapun deskripsi kegiatan yang telah dilakukan pada masing-masing tahap.

\section{Tahap persiapan}

Pada tahap persiapan yang pertama dilakukan adalah mengurus surat perizinan dari perguruan tinggi untuk pelaksanaan kegiatan pengabdian pada masyarakat. Langkah selanjutnya melakukan survei lapangan yang dilakukan oleh tim pengabdian masyarakat (anggota dan dibantu mahasiswa). Kegiatan survei dilakukan untuk mendapatkan informasi tentang hal-hal yang dibutuhkan seperti kesiapan masyarakat sasaran dalam hal ini perwakilan guru-guru di Kabupaten Tuban, kesedian tempat, dan sarana pendukung kegiatan pelatihan (internet, LCD, dan banner). Kemudian menyusun instrumen yang diperlukan dalam kegiatan pelatihan meliputi: (1) Penyusunan materi kegiatan yang berupa Power Point tentang e-resources dan artikel ilmiah; (2) Pembuatan angket respon guru sebagai peserta pelatihan; (3) Penyusunan instrumen penilaian tugas penelusuran e-resources; dan (4) Melakukan koordinasi dengan pihak terkait untuk pelaksanaan kegiatan, sehingga disepakati bahwa kegiatan pengabdian dilakukan tiap hari Minggu sebanyak 4 kali pertemuan dengan pelaksanaan secara luring untuk pertemuan pertama dan 3 pertemuan berikutnya dilaksanakan secara daring karena kondisi COVID-19 masih belum membaik. Pada pertemuan pertama dilakukan secara luring dengan tujuan untuk memberikan pengarahan dan teknik dalam melakukan penelurusuran artikel-artikel yang diperlukan melalui e-resources. 
ABDIMAS: Jurnal Pengabdian Masyarakat Universitas Merdeka Malang

Volume 6, No. 3, August 2021: 395-403

\section{Tahap pelaksanaan}

Kegiatan pada tahap pelaksanaan meliputi: (1) Penyebaran angket pada peserta pelatihan melalui aplikasi Google Form, tujuannya untuk melihat pemahaman peserta pelatihan terhadap aspek-aspek

yang mendukung dalam penulisan artikel ilmiah; (2) Sosialisasi, pada kegiatan sosialisasi menggunakan metode ceramah dengan tujuan untuk memberikan bekal pengetahuan berupa materi pengabdian pada guru-guru tentang bagaimana cara penulusuran melalui e-resources untuk mendapatkan informasi tentang artikel-artikel hasil penelitian, buku, dan informasi lainnya yang diperlukan dalam mendukung penyusunan artikel ilmiah. Selain metode ceramah juga diselingi dengan kegiatan diskusi yang bertujuan untuk membahas hal-hal yang masih belum dipahami oleh guru-guru terkait materi yan diberikan melalui ceramah. Kegiatan ini dilakukan pada pertemuan pertama; (3) Praktik, kegiatan ini bertujuan untuk mengimplementasikan pengetahuan tentang bagaimana cara penelusuran melalui $e$-resources dalam mendapat berbagai informasi yang diperlukan. Pada kegiatan ini menggunakan metode demonstrasi yang dilakukan oleh tim pengabdian. Setelah kegiatan demonstrasi kemudian dilanjutkan dengan praktik langsung yang dilakukan oleh para guru peserta pelatihan dengan didampingi oleh tim pengabdian masyarakat. Kegiatan praktik dilakukan daring sebanyak tiga kali pertemuan.

\section{Tahap evaluasi}

Pada tahap evaluasi aspek yang dinilai berupa: (1) Partisipasi peserta dengan melihat aktivitas guru-guru selama mengikuti kegiatan pelatihan yang selanjutnya didokumentasikan; (2) Pemahaman dari guru-guru peserta pelatihan tentang aspek-aspek yang mendukung penulisan artikel ilmiah. Evaluasi ini tujuannya untuk mengukur pemahaman para guru peserta pelatihan tentang pengetahuan yang terkait dengan (pemahaman mengenai prosiding, jurnal ilmiah, artikel ilmiah, manfaat e-resources, tujuan kajian literatur, Garuda, Sinta, DOAJ, E-journal open access, E-journal sitasi yang berbayar, kegunaan Mendeley, manfaat Google Scholar, tempat jurnal terakreditasi nasional, struktur artikel ilmiah, dan aplikasi cek grammar). Angket tersebut diberikan di pertemuan pertama sebelum kegiatan pelatihan dimulai. Setelah data dari ke-lima belas aspek tersebut terkumpul, selajutnya dipresentasikan antara yang paham dan tidak paham. Kriteria paham apabila peserta menjawab benar terhadap pertanyaan yang diajukan, bila peserta menjawab salah maka dianggap belum paham; (3) Keterampilan para guru peserta pelatihan tentang bagaimana cara menelusuri informasi-informasi melalui e-resources diberikan tugas untuk mencari artikel-artikel hasil penelitian dengan topik dan jumlah artikel yang sudah ditentukan dari Google Advance, Science Direct, Library Genesis, Garuda, Scopus, Proquest, Sinta, dan DOAJ. Jumlah artikel yang dikumpulkan peserta pelatihan dari masing-masing sumber selanjutnya direkap dan diberi skor. Dengan kriteria skor sebagai berikut: (a) Skor (0) bila jumlah artikel yang dikumpulkan (0); (b) Skor (5) bila jumlah artikel yang dikumpulkan (1-3); (c) Skor (10) bila jumlah artikel yang dikumpulkan (4-6); (d) Skor (15) bila jumlah artikel yang dikumpulkan (7-8), dan (e) Skor (20) bila jumlah artikel yang dikumpulkan (9-10). Selanjutnya untuk menentukan nilai keterampilan peserta pelatihan yaitu skor yang diperoleh dibagi skor maksimum X 100. 


\section{HASIL DAN PEMBAHASAN}

Kegiatan pelatihan penulusuran e-resources untuk penyusunan artikel ilmiah bagi guru-guru di Kabupaten Tuban dilaksanakan sebanyak 4 kali pertemuan dengan jumlah peserta 15 orang. Jumlah peserta dibatasi untuk menghindari kerumunan masa mengingat masih dalam kondisi COVID-19. Dari kegiatan pelatihan penulusuran e-resources diperoleh hasil yang berupa: (1) Dokumentasi kegiatan pelatihan pada saat pertemuan pertama yang dilaksanakan secara luring yang disajikan pada Gambar 1-2; (2) Data tentang pemahaman peserta pelatihan terhadap aspek-aspek (pemahaman mengenai prosiding, jurnal ilmiah, artikel ilmiah, manfaat e-resource, tujuan kajian literatur, Garuda, Sinta, DOAJ, E-journal open access, E-journal sitasi yang berbayar, kegunaan Mendeley, manfaat Google Scholar, tempat jurnal terakreditasi nasional, struktur artikel ilmiah, dan aplikasi cek grammar) yang mendukung dalam penyusunan artikel ilmiah yang disajikan pada Gambar 3; (3) Data tentang keterampilan peserta pelatihan dalam mencari artikel dengan penulusuran melalui e-resource (Science Direct, Google advance, Scopus, DOAJ, Library genesis, Garuda, Sinta) pada Tabel 1.
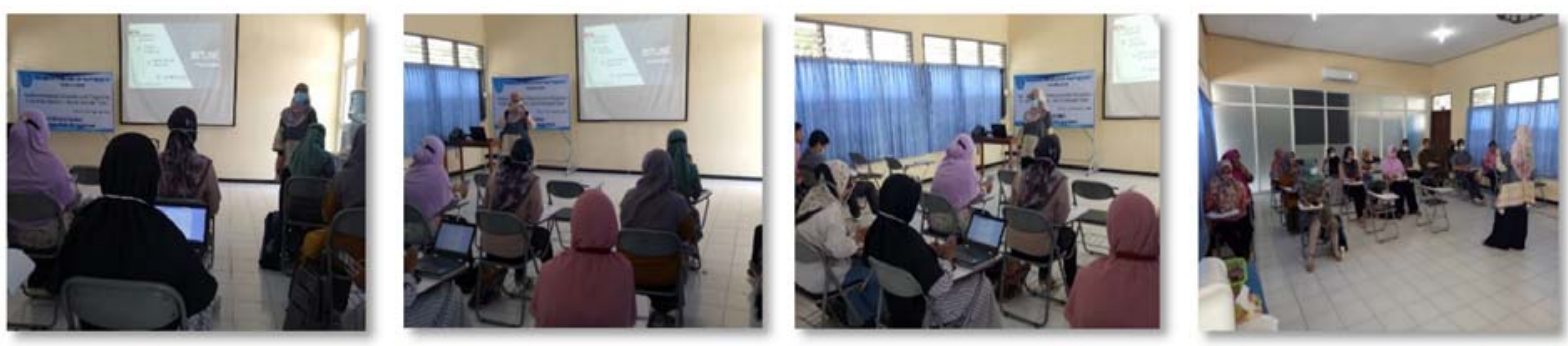

Gambar 1. Kegiatan penyebaran angket dan sosialisasi

Gambar 2. Kegiatan praktik penulusuran e-resources dan tanya jawab

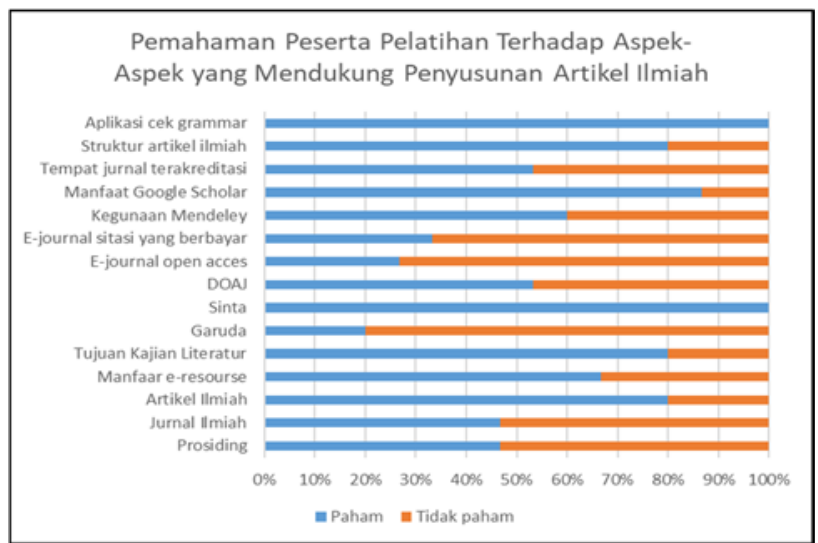

Gambar 3. Pemahaman peserta pelatihan terhadap aspek-aspek yang mendukung penysunan artikel ilmiah 
ABDIMAS: Jurnal Pengabdian Masyarakat Universitas Merdeka Malang Volume 6, No. 3, August 2021: 395-403

Tabel 1. Data keterampilan peserta pelatihan dalam mencari artikel dengan penulusuran melalui e-resources

\begin{tabular}{|c|c|c|c|c|c|c|c|c|c|c|c|c|c|}
\hline \multicolumn{2}{|c|}{ Sinta } & \multicolumn{2}{|c|}{ DOAJ } & \multicolumn{2}{|c|}{ Scopus } & \multicolumn{2}{|c|}{$\begin{array}{c}\text { Science } \\
\text { Direct }\end{array}$} & \multicolumn{2}{|c|}{$\begin{array}{l}\text { Google } \\
\text { Advance }\end{array}$} & \multicolumn{2}{|c|}{ Garuda } & \multicolumn{2}{|c|}{ Library Genesis } \\
\hline Nilai & Frek. & Nilai & Frek. & Nilai & Frek. & Nilai & Frek. & Nilai & Frek. & Nilai & Frek. & Nilai & Frek. \\
\hline 100 & 13 & 100 & 15 & 100 & 10 & 100 & 12 & 100 & 13 & 100 & 12 & 100 & 10 \\
\hline 80 & 1 & & & 80 & 3 & 75 & 3 & 75 & 2 & 90 & 1 & 90 & 1 \\
\hline \multirow[t]{2}{*}{60} & 1 & & & 60 & 2 & & & & & 75 & 2 & 75 & 2 \\
\hline & & & & & & & & & & & & 60 & 2 \\
\hline \multicolumn{2}{|c|}{ Rata-Rata } & \multicolumn{2}{|c|}{ Rata-Rata } & \multicolumn{2}{|c|}{ Rata-Rata } & \multicolumn{2}{|c|}{ Rata-Rata } & \multicolumn{2}{|c|}{ Rata-Rata } & \multicolumn{2}{|c|}{ Rata-Rata } & \multicolumn{2}{|c|}{ Rata-Rata } \\
\hline \multicolumn{2}{|c|}{96} & \multicolumn{2}{|c|}{100} & \multicolumn{2}{|c|}{91} & \multicolumn{2}{|c|}{95} & \multicolumn{2}{|c|}{97} & \multicolumn{2}{|c|}{96} & \multicolumn{2}{|c|}{91} \\
\hline
\end{tabular}

Berdasarkan Gambar 3, terlihat bahwa pemahaman peserta pelatihan yang kurang dari $60 \%$ meliputi tempat jurnal terakreditasi (Sinta), e-journal sitasi yang berbayar, e-journal open access, DOAJ, Garuda, jurnal ilmiah, dan prosiding. Hal ini menunjukkan bahwa pemahaman peserta pelatihan tentang e-resources masih rendah. Padahal e-resources yang perkembangannya saat ini sedemikian pesat telah memberikan pengaruh signifikan terhadap komunitas akademik dalam hal pemanfaatan informasi. Diantara jenis e-resources yang diperlukan dalam penyusunan artikel adalah e-journal dan e-book (Kurniawan, 2020).

Banyak hal yang bisa ditelusuri dari e-resources seperti Proquest dan EBSCO yang menyediakan sumber daya elektronik berbasis data lengkap agregasi seperti e-journal, e-book, e-proceeding, dan e-paper. Kemudian Scopus dan Proquest Abstract menyediakan informasi atau sumber daya informasi berbasis data indeks dan abstrak, namun dilengkapi dengan analisis terhadap dokumen yang ada misal analisis sitiran (Johnson et al., 2012). Contoh lainnya Science Direct merupakan database ilmiah internasional terkemuka yang menawarkan dan menyediakan informasi ilmiah full-text dalam bentuk jurnal dan buku. Science Direct menyediakan lebih dari 11 juta artikel dengan pertumbuhan konten database mencapai 0,5 juta per tahun. Science Direct adalah bagian dari Elsevier, yaitu sebuah perusahaan yang menyediakan informasi ilmiah (Nashihuddin \& Raha, 2013).

Oleh karena itu, e-journal memainkan peran utama dalam karya ilmiah setiap akademisi. E-journal merupakan pilihan yang tepat bagi para akademisi karena lebih menghemat waktu, membuat pekerjaan lebih mudah, menghasilkan penelitian yang berkualitas, dan memungkinkan para akademisi menemukan lebih banyak bahan dibandingkan dengan jurnal cetak. Namun kemudahan aksesibilitas dari berbagai e-journal tergantung pada internet (Ariffin \& Bakar, 2013). Dari hasil studi Ollé \& Borrego (2010) bahwa e-journal berdampak terhadap prilaku ilmiah para akademisi, mereka lebih banyak baca jurnal dan artikel dari pada sebelumnya. Pentingnya pelatihan dalam penggunaan e-resources telah disoroti di banyak tempat. Dari beberapa penelitian merekomendasikan tentang pentingnya pelatihan bagi para pengguna e-resources dalam pencarian informasi (Siwach \& Malik, 2019).

Oleh karena itu, bagi guru-guru pelatihan dalam penulusuran e-resources akan bermanfaat, dalam mengatasi permasalahan keterbatasan dalam mencari sumber literatur yang banyak dan up-to-date. 


\section{Pelatihan Penelusuran E-Resources untuk Penyusunan Artikel Ilmiah bagi Guru-Guru di Kabupaten Tuban \\ Imas Cintamulya, Mu'jizatin Fadiana}

Selama ini guru-guru dalam penyusunan artikel ilmiah hanya mengandalkan literatur dari buku-buku yang ada di perpustakaan dengan tahun yang sudah lama atau cari literatur dari Google. Penulusuran melalui e-resources sebenarnya tidak rumit, namun kebanyakan para guru belum mengenal dan belum terbiasa mencari informasi melalui e-resources.

Hasil pelatihan penulusuran e-resources untuk penyusunan artikel ilmiah bagi guru-guru di Kabupaten Tuban menunjukkan bahwa rata-rata nilai peserta pelatihan untuk masing-masing Science Direct, Google Advance, Garuda, Library Genesis, Sinta, DOAJ, dan Scopus nilainya berada di atas 90 (Tabel 1). Ini berarti bahwa melalui pelatihan penulusuran e-resources keterampilan guru-guru dalam mencari informasi untuk mendukung penyusunan artikel ilmiah sudah sangat baik. Diharapkan para guru peserta pelatihan akan lebih mudah, lebih banyak informasi yang dikumpulkan, serta informasinya lebih up-to-date.

Menurut Fidel \& Green (2004) ada tiga hal dalam keberhasilan pencarian sumber informasi di database yaitu: (1) Kefokusan isi materi informasi yang dicari; (2) Keandalan sistem pencarian; dan (3) Pemahaman menganalisis konten informasi. Ketiga kunci inilah yang diberikan kepada guru-guru saat mengikuti pelatian penulusuran e-resources sehingga mereka berhasil mencari sumber informasi berupa artikel ilmiah dari Science Direct, Google Advance, Garuda, Library Genesis, Sinta, DOAJ, dan Scopus. Lebih jauh Fidel \& Green (2004) menjelaskan bahwa dari hasil temuan aksesibilitas merupakan faktor utama dalam pemilihan sumber informasi.

Varibel peserta yang mempengaruhi keterampilan penggunaan e-resources adalah jenis kelamin, kelompok umur, tujuan, spesialisasi, dan jenis institusi (Thanuskodi \& Kumar, 2017). Berdasarkan pada variabel yang mempengaruhi keterampilan penggunaan $e$-resources pada kegiatan pelatihan penulusuran e-resources untuk penyusunan artikel ilmiah bagi guru-guru di Kabupaten Tuban adalah tujuan yang hendak dicapai. Rata-rata guru-guru mengikuti pelatihan karena bertujuan supaya bisa menulis artikel dengan baik dan benar sesuai kriteria. Variabel inilah yang mendorong para guru untuk bisa terampil dalam penulusuran e-resources. Hal ini terungkap dari diskusi dan tanya jawab rata-rata mereka belum mengenal tentang manfaat e-resources dalam mendukung penulisan artikel ilmiah sehingga mereka dalam menulis artikel belum sesuai dengan kriteria yang diminta. Para peserta dalam memenuhi tugas untuk mencari artikel-artikel sama seperti kegiatan pelatihan lainnya yaitu mencari artikel dari journal open acess karena kelebihannya para peserta dapat download artikel tanpa harus bayar. Hal ini yang memotivasi para peserta untuk menggunakan e-resources dalam mencari artikel-artikel yang diperlukan. Perangkat yang digunakan peserta untuk penulusuran e-resources terutama ponsel dan laptop.

Sebagai pembanding, beberapa pelatihan dari e-resources telah menunjukkan manfaat yang penting bagi para peserta pelatihan. Rata-rata para peserta memiliki tingkat keterampilan dalam menggunakan e-resources. Para peserta memiliki kesadaran tentang banyak informasi yang tersedia melalui e-resources. Sebagian besar dari peserta pelatihan lebih banyak menggunakan journal open access. Perangkat yang banyak digunakan oleh peserta pelatihan anatara lain ponsel, tablet, dan laptop (Thanuskodi \& Kumar, 2017). 
ABDIMAS: Jurnal Pengabdian Masyarakat Universitas Merdeka Malang Volume 6, No. 3, August 2021: 395-403

\section{SIMPULAN DAN SARAN}

Pelatihan penulusuran e-resources untuk penyusunan artikel ilmiah bagi guru-guru di Kabupaten Tuban telah meningkakan pemahaman dan keterampilan guru-guru peserta pelatihan dalam mencari informasi berupa artikel ilmiah maupun buku dari Science Direct, Google Advance, Garuda, Library Genesis, Sinta, DOAJ, dan Scopus. Kegiatan pelatihan penulusuran e-resources membantu menyelesaikan masalah yang dihadapi guru dalam penulisan artikel terkait menggunakan sumber primer, pustaka yang mutakhir, dan penulisan kutipan yang konsisten dengan mengikuti salah satu gaya, serta penulisan daftar pustaka yang konsisten mengikuti salah satu gaya. Oleh karena itu, pemahaman dan keterampilan dalam mencari informasi ini sangat berguna bagi guru-guru dalam pembuatan karya ilmiah berupa artikel sebagai upaya untuk meningkatkan profesionalisme guru.

Pelatihan penulusuran e-resources untuk penyusunan artikel ilmiah bagi guru-guru di Kabupaten Tuban yang sudah dilaksanakan, perlu untuk diperluas sasaran pesertanya. Sasaran peserta bisa diperluas tidak hanya 15 orang. Karena kegiatan ini terbukti memberikan dampak positif bagi guru. Untuk menunjang kewajiban guru menulis artikel ilmiah, pemahaman dan keterampilan penulusuran e-resources penting dan dibutuhkan guru-guru. Oleh karena itu, perlu ada pelatihan semacam ini lagi untuk guru-guru dari perwakilan sekolah lainnya berdasarkan jenjangnya (SD, SMP, SMA).

\section{UCAPAN TERIMA KASIH}

Pada kesempatan ini kami tim pengabdian pada masyarakat mengucapkan banyak terima kasih kepada Pascasarjana Universitas PGRI Ronggolawe yang telah mendukung terlaksananya kegiatan pelatihan penulusuran e-resources untuk penyusunan artikel ilmiah bagi guru-guru di Kabupaten Tuban. Tak lupa kami juga mengucapkan terima kasih kepada para guru peserta pelatihan yang telah berantusias mengikuti pelatihan sampai selesai serta tim sarana prasana yang telah membantu menyiapkan peralatan yang diperlukan dalam kegiatan pelatihan ini.

\section{DAFTAR PUSTAKA}

Adegbore, A. M. (2011). University faculty use of electronic resources: A review of the recent literature. PNLA Quarterly, 75(4), 1-7.

Ariffin, M. Y. M., \& Bakar, A. A. (2013). The challenges in the usage of e-journal amongst lecturers at a public university. Procedia-Social and Behavioral Sciences, 103, 975-981. https://doi.org/10.1016/j.sbspro.2013.10.421

Depdiknas Dirjen Dikdasmen Direktorat Tenaga Kependidikan. (2001). Pedoman Penyusunan Karya Tulis Ilmiah di Bidang Pendidikan dan Angka Kredit Pengembangan Profesi Guru. Jakarta.

Elavazhagan, K., \& Udayakumar, M. S. (2013). Use of e-resources in the BITS, Pilani-Hyderabad Campus: A Study. International Research Journal of Library \& Information Science, 3(3), 470-479.

Fidel, R., \& Green, M. (2004). The many faces of accessibility: engineers' perception of information sources. Information Processing \& Management, 40(3), 563-581.

https://doi.org/10.1016/S0306-4573(03)00003-7 
Johnson, S., Evensen, O. G., Gelfand, J., Lammers, G., Sipe, L., \& Zilper, N. (2012). Key issues for e-resource collection development: a guide for libraries. Den Haag: IFLA The Hague.

Kurniawan, K. (2020). Kebijakan pengembangan koleksi e-resources di Perpustakaan UIN Sunan Kalijaga Yogyakarta. LIBRIA, 12(1), 71-88.

Maryatun, M., \& Irianti, P. (2016). Pemanfaatan database EBSCO dan ProQuest sebagai rujukan penyusunan tesis dan disertasi bagi mahasiswa Program Magister Sains dan Doktor Fakultas Ekonomika dan Bisnis UGM: Analisis sitiran jurnal ilmiah. Berkala Ilmu Perpustakaan dan Informasi, 12(2), 123-135. https://doi.org/10.22146/bip.17291

McMillen, P. S., Garcia, J., \& Bolin, D. A. (2010). Promoting professionalism in master's level teachers through research based writing. The Journal of Academic Librarianship, 36(5), 427-439. https://doi.org/10.1016/j.acalib.2010.06.007

Mondal, D., \& Maity, A. (2016). Selection and acquisition of e-resource collection in selected libraries of R\&D institutions in Kolkata city: A survei of current practices. International Research: Journal of Library and Information Science, 6(3), 540-553.

Moutafidou, A., Melliou, K., \& Georgopoulou, A. A. (2012). Educational research and teacher development. Procedia-Social and Behavioral Sciences, 31, 156-161. https://doi.org/10.1016/j.sbspro.2011.12.034

Nashihuddin, W., \& Raha, R. N. (2013). Aksesibilitas informasi ilmiah Science Direct Pustaka Ristek di lingkungan Ristek dan LPNK. Jurnal Pustakawan Indonesia, 12(2), 1-9. https://doi.org/10.29244/jpi.v12i2.11493

Ollé, C., \& Borrego, Á. (2010). A qualitative study of the impact of electronic journals on scholarly information behavior. Library \& Information Science Research, 32(3), 221-228.

https://doi.org/10.1016/j.lisr.2010.02.002

Siwach, A. K., \& Malik, S. K. (2018). E-Resource use by Science Faculty and Research Scholars: A case study of Panjab University, Chandigarh (India). Journal of Advancements in Library Sciences, $5(2), 27-35$.

Siwach, A. K., \& Malik, S. K. (2019). Use of electronic resources by science faculty and researchers in selected North Indian universities. Library Philosophy and Practice, 1-25.

Smiles, T. L., \& Short, K. G. (2006). Transforming teacher voice through writing for publication. Teacher Education Quarterly, 33(3), 133-147.

Thanuskodi, S., \& Kumar, A. A. (2017). Usage of Electronic Resources among Ophthalmologists. Library Philosophy \& Practice, 1-15.

Uplaonkar, S. S., \& Keshava, K. (2013). Use of electronic information sources and services in S. Nijalingappa Medical College: A study. Library Progress (International), 33(1), 1-11. 